\title{
Non-Invasive Early Molecular Detection of Gastric Cancers
}

\author{
Hiroyuki Yamamoto ${ }^{1, *(\mathbb{D})}$, Yoshiyuki Watanabe ${ }^{1,2} \mathbb{D}$, Yoshinori Sato ${ }^{1}$, Tadateru Maehata ${ }^{1}$ and \\ Fumio Itoh ${ }^{1}$ \\ 1 Division of Gastroenterology and Hepatology, Department of Internal Medicine, St. Marianna University \\ School of Medicine, Kawasaki 216-8511, Japan; ponponta@marianna-u.ac.jp (Y.W.); \\ y2satou@marianna-u.ac.jp (Y.S.); t2maehata@marianna-u.ac.jp (T.M.); fitoh@marianna-u.ac.jp (F.I.) \\ 2 Department of Internal Medicine, Kawasaki Rinko General Hospital, Kawasaki 210-0806, Japan \\ * Correspondence: h-yama@marianna-u.ac.jp; Tel.: +81-44-977-8111
}

Received: 31 August 2020; Accepted: 4 October 2020; Published: 7 October 2020

Simple Summary: This paper reviewed an update on the molecular detection of gastric cancers, focusing on various diagnostic approaches, including nonblood analytes, specifically gastric juices or washes. This comprehensive review demonstrates how liquid biopsy may be beneficial in identifying and optimizing new diagnostic approaches for gastric cancer.

\begin{abstract}
Gastric cancer (GC) is a significant source of global cancer death with a high mortality rate, because the majority of patients with GC are diagnosed at a late stage, with limited therapeutic choices and poor outcomes. Therefore, development of minimally invasive or noninvasive biomarkers which are specific to GC is crucially needed. The latest advancements in the understanding of GC molecular landscapes and molecular biological methods have accelerated attempts to diagnose GC at an early stage. Body fluids, including peripheral blood, saliva, gastric juice/wash, urine, and others, can be a source of biomarkers, offering new methods for the early detection of GC. Liquid biopsy-based methods using circulating sources of cancer nucleic acids could also be considered as alternative strategies. Moreover, investigating gastric juices/washes could represent an alternative for the detection of GC via invasive biopsy. This review summarizes recently reported biomarkers based on DNA methylation, microRNA, long noncoding RNA, circular RNA, or extracellular vesicles (exosomes) for the detection of GC. Although the majority of studies have been conducted to detect these alterations in advanced-stage GC and only a few in population studies or early-stage GC, some biomarkers are potentially valuable for the development of novel approaches for an early noninvasive detection of GC.
\end{abstract}

Keywords: liquid biopsy; DNA methylation; microRNA; long noncoding RNA; circular RNA; extracellular vesicles; gastric juice; gastric wash

\section{Introduction}

Gastric cancer (GC) is the fifth most frequently diagnosed cancer (one million new cases) and the third cause of yearly cancer deaths (781,000 deaths) worldwide [1]. It is a diverse cancer with various environmental etiologic factors and alternate tumorigenic pathways (Figure 1) [2,3]. One of its main etiologies is a persistent Helicobacter pylori (H. pylori) infection, but only a minor fraction of people with H. pylori infection develop GC [4,5]. The combination of gastroscopy with biopsy remains the standard method for the screening and diagnosis of GC $[6,7]$. 


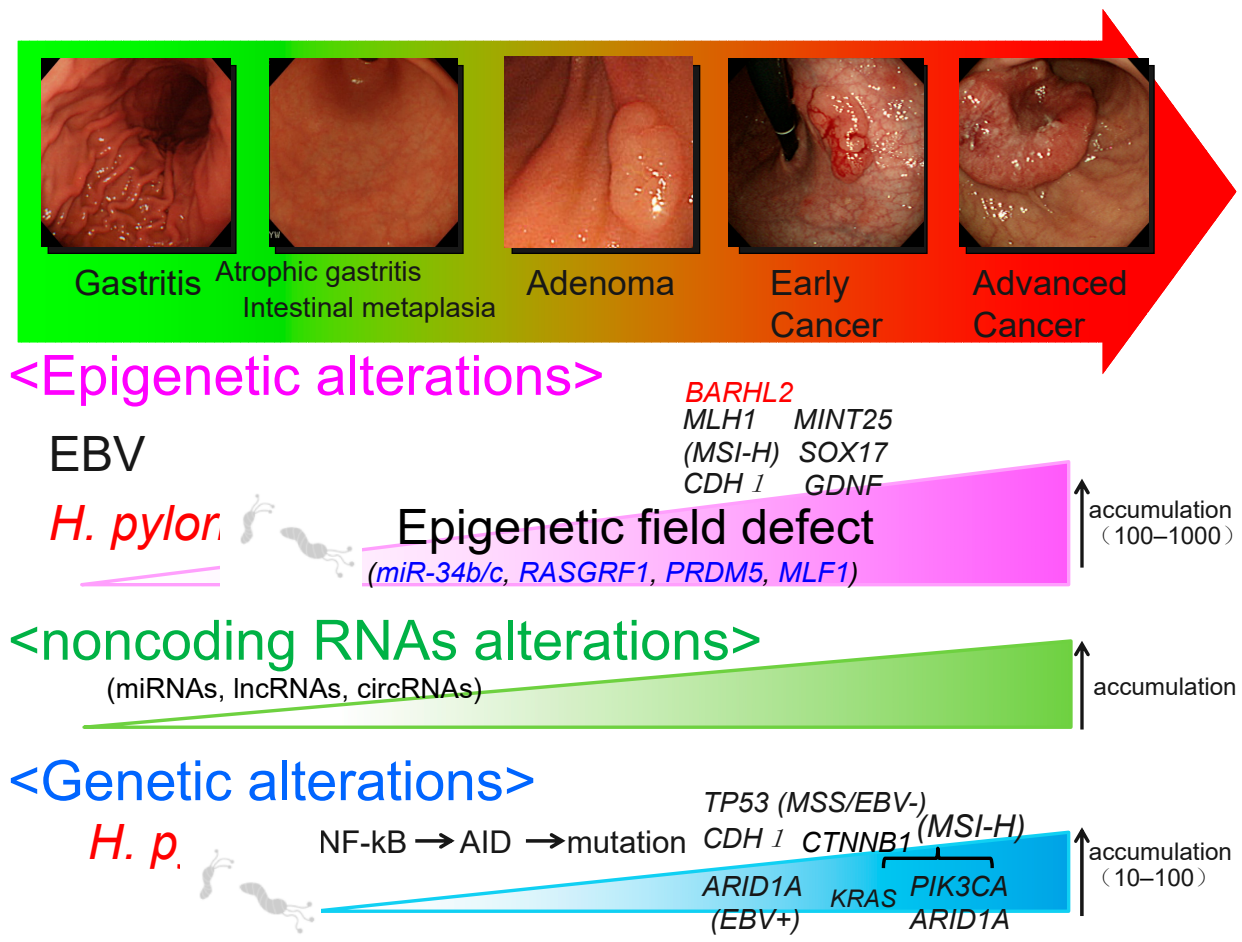

Figure 1. Molecular alterations in gastric carcinogenesis. The model for gastric carcinogenesis is presented based on alterations in genome, epigenome, and noncoding RNAs. Methylation of the genes in blue appears to be involved in an epigenetic field defect. H. pylori: Helicobacter pylori; MSI-H: Highfrequency microsatellite instability; EBV: Epstein-Barr virus.

Early detection, therapy, and precise monitoring of GC is important for improving the clinical course of patients. However, CG is mainly diagnosed using invasive methods, which sometimes have adverse events [6]. Endoscopic biopsy is the gold standard for the diagnosis of GC. The molecular analysis of specimens of advanced GC also helps to choose the therapeutic strategy. However, in certain cases, endoscopic biopsy cannot be performed, simply due to its invasiveness. Moreover, biopsy specimens do not always reflect tumor dynamics and drug sensitivities. New noninvasive biomarkers that can monitor real-time tumor dynamics are necessary for an early diagnosis, prediction of prognosis and recurrence, and evaluation of therapeutic efficacy.

Although the incidence of GC is decreasing, the survival rate remains low, mostly because many patients are asymptomatic until it reaches the late stage. Subsequently, development of noninvasive and/or minimally invasive methods for an early detection of GC is crucial to decrease GC deaths $[8,9]$. The newest progress in molecular characterization of GC has provided novel diagnostic and/or therapeutic approaches potentially used in clinical settings. In this review, possible clinical applications and prospects of minimally invasive and/or noninvasive biomarkers for the early detection of GC are summarized.

\section{Epigenetic Alteration}

Genomic and epigenomic modifications play important roles in GC pathogenesis [10-13]. Epigenetic regulation is necessary for the normal growth and continuation of tissue-specific gene expression patterns in mammals. Therefore, epigenetic alterations could result in impaired gene function and, eventually, malignant transformation [14]. Diverse alterations have been reported in the epigenetic mechanism of GC, including DNA methylation, nucleosome positioning, and histone modification [15-19]. Promoter CpG island hypermethylation results in silencing of tumor suppressor and tumor-associated genes, the most distinct epigenetic hallmark of GC. Gene hypermethylation with various biological functions has been reported in GC [15-19]. DNA methylation is a potent source 
of possible diagnostic biomarkers for GC screening [20]. Therefore, as noninvasive biomarkers of GC, DNA hypermethylation detected in body fluids, including peripheral blood, saliva, gastric wash, or urine, may be clinically important. Aberrant DNA methylation of various genes in body fluids could be a valuable biomarker for the early detection of GC (Figure 2) [17].

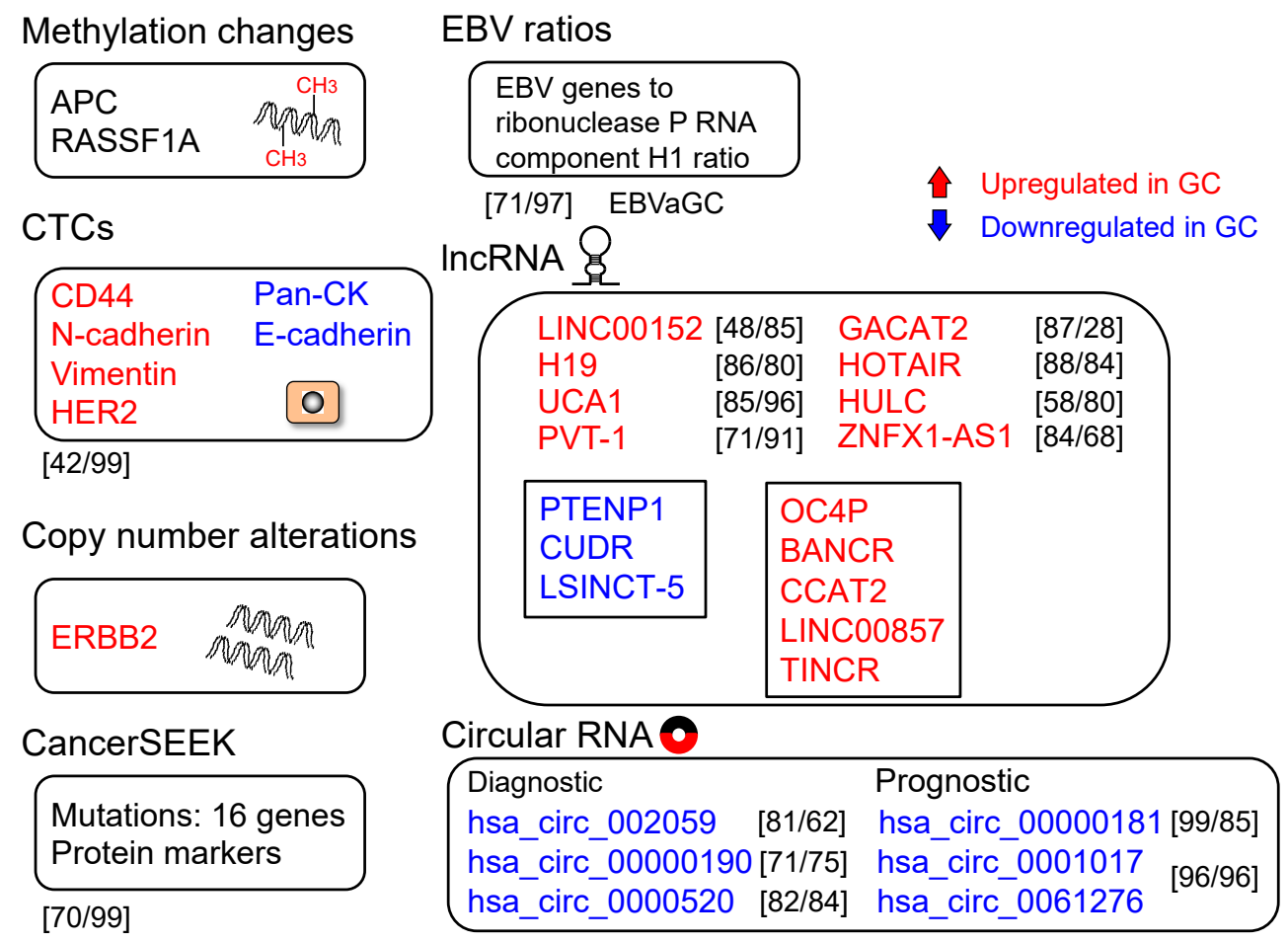

Figure 2. Molecular targets with the potential as diagnostic biomarkers for gastric cancer (GC). Upregulated (in red) and downregulated (in blue) markers are shown. Sensitivity and specificity are shown in square brackets.

\section{MicroRNAs (miRNAs)}

A miRNA is a small (19-25 nucleotides) noncoding RNA sequence, which controls gene expression in the post-transcriptional phase. miRNAs are crucial for various cellular functions, such as differentiation, growth, and apoptosis [21-25]. Depending on the role of the target mRNA/gene, miRNAs function as tumor suppressor genes or oncogenes. Altered miRNA expression patterns in tumors are caused by various mechanisms, including genetic mutation, DNA copy number alterations, incorrect transactivation, suppression of transcription via oncogenic factors, impaired post-transcriptional process, or transcriptional silencing related to the aberrant methylation of the promoter CpG islands.

Alterations in miRNA expression play a crucial role in gastric tumorigenesis [26-29]. Various miRNAs with diverse biological functions have been impaired in GC. Since tumor-derived miRNAs are present in the circulation, their levels can be quantified. Therefore, circulating miRNAs are potential diagnostic biomarkers for GC [28]. The clinical applications of altered miRNAs as noninvasive diagnostic biomarkers or therapeutic targets have certainly been described (Figure 3) [30]. miRNA isoforms are constantly expressed in a tissue- and disease-specific manner [31]. Next-generation sequencing is the most efficient technique for profiling miRNAs, resulting in the discovery of altered miRNAs with possible clinical applications. 

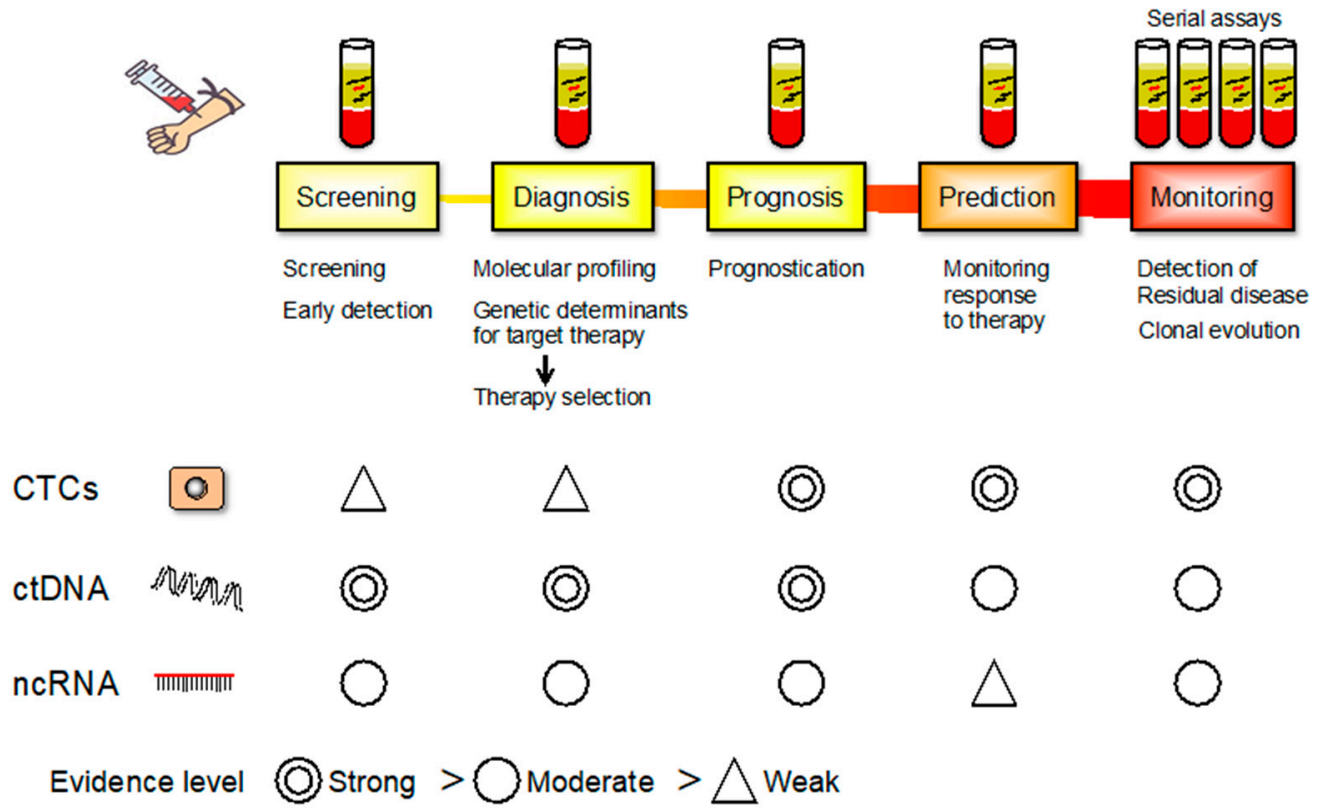

Figure 3. Potential applications of liquid biopsies during the course of GC management. Evidence level is shown.

MicroRNAs are often deregulated in a stepwise manner from chronic gastritis to preneoplastic disorders, including atrophic gastritis/intestinal metaplasia, dysplasia, and early and advanced cancer [32]. Therefore, possible diagnostic applications based on miRNA expression analysis have been reported [32]. Figure 4 summarizes the potential miRNA biomarkers for the detection of GCs.

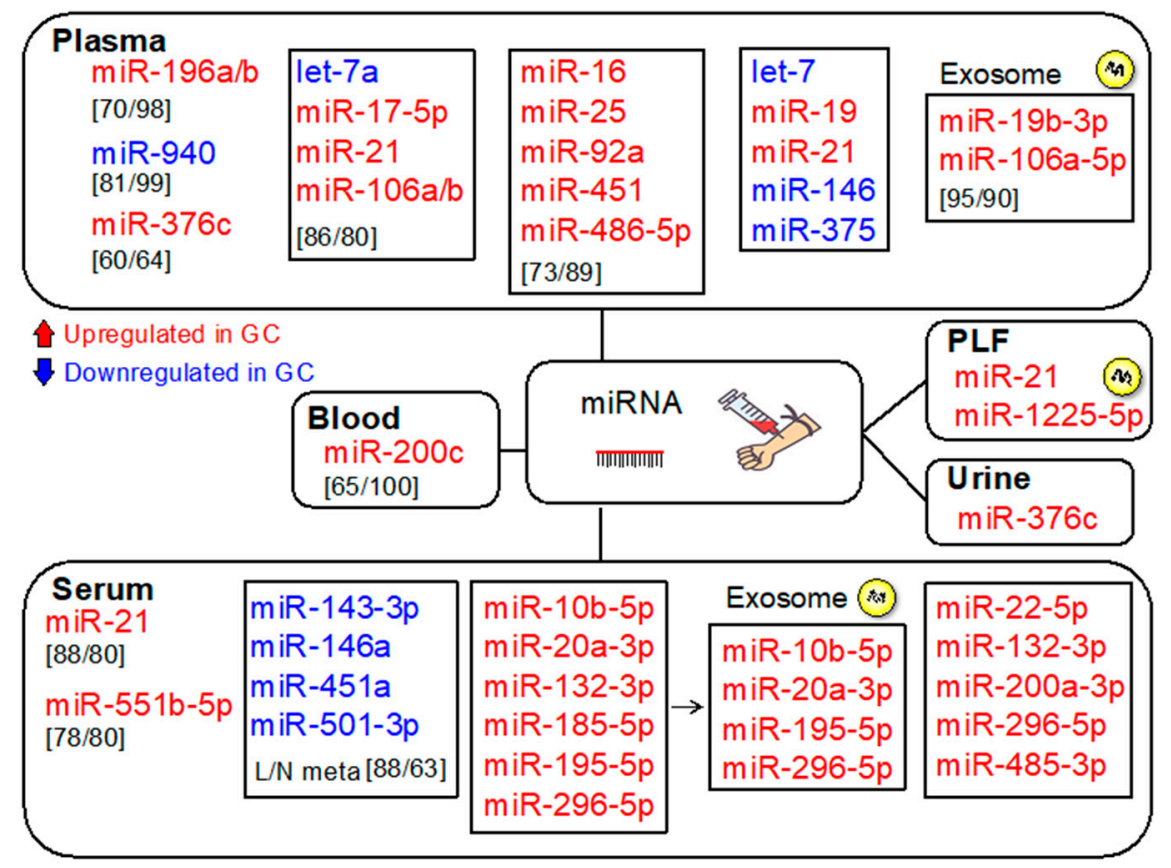

Figure 4. miRNAs potentially considered as diagnostic biomarkers for GC. Upregulated (in red) and downregulated (in blue) miRNAs are shown. Sensitivity and specificity are shown in square brackets. PLF: peritoneum lavage fluid.

Serum miRNA-21 levels were elevated in patients with GC, and the positive prediction rate (PPR) was 88\%, whereas PPRs of CA19-9 and carcinoembryonic antigen (CEA) were 50\% and 46\%, 
respectively. The rate was $89 \%$ for stage I GC [33]. Circulating plasma miR-196a showed a higher diagnostic capability than miR-196b or combined miR-196a/b, emphasizing its ability as a potentially useful GC biomarker [34]. Plasma levels of miR-376c were also validated as a GC biomarker, even for patients with early-stage GC [35]. miR-376c levels were also elevated in the urine of patients with GC. Urinary miR-376c predicted GC with an area under the curve (AUC) of 0.70 , sensitivity of $60 \%$, and specificity of $64 \%$ [35]. Urine sample collection is easier and noninvasive compared with that of plasma [36,37]. If these results are further validated, urinary miR-376c will be a potentially valuable noninvasive biomarker for GC.

A panel of five plasma miRNAs (miR-16, miR-25, miR-92a, miR-451, and miR-486-5p) presented a high diagnostic ability for GC at the early stage (AUCs of 0.989 for the training and validation set and 0.812 for the validation set), suggesting that this panel potentially functions as a noninvasive biomarker for early-stage GC [38]. A panel of six upregulated miRNAs (miR10b-5p, miR-20a3p, miR132-3p, miR185-5p, miR195-5p, and miR296-5p) showed diagnostic accuracy for GC (AUCs of 0.764 for the training set and 0.702 for the validation set) [39]. Among them, miR10b-5p, miR20a-3p, miR195-5p, and miR296-5p were also elevated in serum exosomes of patients with GC. Importantly, not all circulating miRNAs are released from exosomes [40]. Argonaute2 complexes reportedly transport a subset of circulating miRNAs, irrespective of vesicles in the plasma [41].

A panel of five upregulated serum miRNAs (miR-22-5p, miR-132-3p, miR-200a-3p, miR-296-5p, and miR-485-3p) showed diagnostic accuracy for cardia GC (AUCs of 0.766 for the training set and 0.724 for the validation set) [42]. Exosomal miR-19b-3p, miR-106a-5p, and their combination discriminated GCs from non-GCs with AUCs of $0.769,0.786$, and 0.814 , respectively. Moreover, this combination distinguished GC from non-GC with $95 \%$ sensitivity and $90 \%$ specificity in the validation set [43]. miR-21 and miR-19 have been shown to increase and let-7, miR-146, and miR-375 decrease in $H$. pylori-infected GC patients, suggesting the potential of these miRNAs as biomarkers for the early detection of GC [44].

Recent findings suggest the role of miRNAs in the regulation of gastric cancer stem cells (GCSCs). A better understanding on molecular mechanisms and target genes involved in the GCSC regulation could accelerate the development of new strategies in the early detection of GC [45].

\section{Epigenetic Field Defects and miR-34b/c Methylation}

Aberrant CPG island hypermethylation is often associated with miRNA silencing. MicroRNA-34b/c methylation was frequently detected in GCs (83/118,70\%) [46]. Moreover, methylation levels in the gastric mucosa of patients with multiple GCs were higher than in those of patients with single GC or non-GC individuals with $H$. pylori infection. These findings suggest that miR-34b/c methylation is implicated in a gastric epigenetic field defect and could be a promising biomarker to analyze the risk of multiple GCs.

After an endoscopic resection of a primary GC, a secondary GC could develop metachronously. However, predicting the development of metachronous GC based on clinicopathological features of primary GC alone is difficult. DNA hypermethylation in the nontumor gastric mucosa is involved in tumorigenesis and could be a valuable biomarker for GC risk. In a prospective study of 129 patients with early GC after the curative endoscopic resection, metachronous GCs occurred in 17 patients (13\%) [47]. Multivariate analysis indicated that miR-34b/c methylation in the gastric body is an independent predictive marker for the occurrence of metachronous GC, suggesting its clinical application.

\section{Circulating Tumor Cells (CTCs)}

Circulating tumor cells are a heterogeneous population of cells originating from primary tumors that enter the bloodstream, representing an essential step in hematogenous metastasis (Figure 5). As a liquid biopsy, CTCs have received considerable attention because they are easily accessible in the peripheral blood and can also be used to monitor tumor dynamics (Figure 3) [48]. Due to CTC heterogeneity, various methodologies have been developed to isolate and count them based on specific 
molecular or phenotypic characteristics. Detection of CTC is potentially useful for evaluating tumor dynamics and for monitoring GC treatment responses (Figure 3) [49].

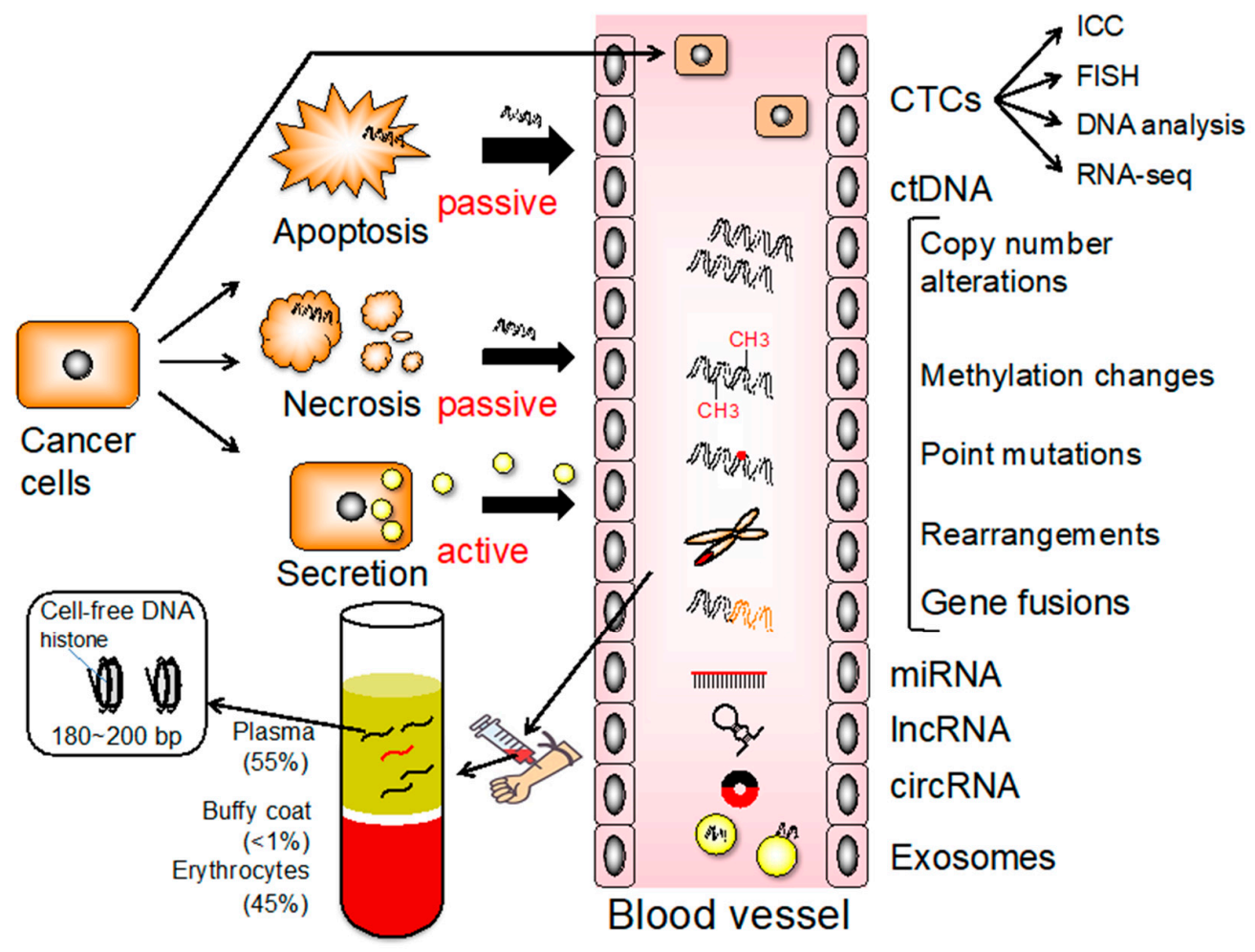

Figure 5. Origins and range of alterations in liquid biopsies. Left bottom, cell-free DNA (cfDNA) predominantly consists of nucleosome-protected DNA shed into the bloodstream by cells undergoing apoptosis.

The gastric tissue adjacent to the tumor reportedly shows an aberrant gene signature and biological characters, suggesting molecular characteristics partly different from both GC and healthy tissues. Therefore, using the gastric tissue adjacent to the tumor as a healthy control tissue in the analysis could lead to inappropriate results. Using circulating sources of biomarkers may be less laborious and misleading. Conversely, the methodology using a differential gene expression among normal, adjacent, and tumor tissues could help to specifically identify cancer biomarkers that could be used as targets on CTCs [50].

According to a meta-analysis of the diagnostic accuracy of diverse CTC detection procedures, the combined sensitivity and specificity of CTCs for GC were 42\% and 99\%, respectively (Figure 2) [51]. Epithelial cell adhesion molecule (EpCAM) is a CTC marker in various cancer types, whereas cluster of differentiation 44 (CD44) is a GCSC marker. The sensitivity and specificity of EpCAM+CD44+ cell detection to identify patients with GC were $92.3 \%$ and $100 \%$, respectively, suggesting that CD $44+$ CTCs are a candidate biomarker for the detection of GC [52]. Despite the fact that challenges in techniques remain, CTCs are still potential biomarkers for the detection of GC [53].

\section{Cell-Free DNA (cfDNA)}

Circulating tumor DNA (ctDNA) has been identified as a potentially useful biomarker for the early detection of cancer, prediction of prognosis, detection of therapeutic targets, and real-time monitoring of tumor dynamics (Figure 3). Deriving from primary and/or metastatic tumors, ctDNA can be used for various analyses, such as genetic mutations, rearrangements, copy number variations, and methylation status (Figure 5) [54]. Various cancer-specific genetic and/or epigenetic alterations have been examined as possible ctDNA-based biomarkers for the early detection of GC [20]. Tumor-specific SNVs and gene 
amplifications can be detected in the plasma of a majority of patients with GC (Figure 2) [55]. Analyzing the copy number variation is more challenging due to the short length and uneven distribution of ctDNAs [54].

In general, ctDNA represents a fraction of cfDNA that is substantially increased in late-stage tumors [56]. However, ctDNA could be detected in patients with tumors at an early stage [57,58]. Methylation of the promoter of various genes in ctDNA has been frequently detected in patients with early-stage GC (Figure 2). CancerSEEK is a unique, multianalyte blood test that concurrently analyzes mutations and cancer-related protein biomarkers. Circulating tumor DNA-based multiplex polymerase chain reaction (PCR) analysis can detect mutations at 2001 genomic loci of 16 genes, whereas protein biomarker levels are analyzed using immunoassays. The sensitivity and specificity for GC were $70 \%$ and $>99 \%$, respectively, with only 7 out of 812 control individuals being positive [59]. This assay combines ctDNA and protein biomarkers to increase the diagnostic accuracy and support in the identification of specific tumors, including GC [60].

Moreover, cfDNA could reportedly recognize Epstein-Barr virus (EBV)-associated gastric carcinoma (EBVaGC) and monitor cancer dynamics [61]. Using EBV genes-to-ribonuclease P RNA component $\mathrm{H} 1$ ratios (EBV ratios) analyzed using quantitative real-time PCR, cell-free EBV DNA was found in patients with GC with a sensitivity of $71 \%$ and specificity of $97 \%$. The plasma EBV ratios in patients with EBVaGC decreased after treatment and increased during tumor progression/recurrence. The plasma EBV ratio appears to be useful for the recognition of EBVaGC and/or for real-time monitoring of tumor dynamics. Analysis of ctDNA is possibly a sensitive procedure for the detection of low-frequency mutations; however, further studies are necessary to verify if and how the analyses could be used in a clinical setting [55].

\section{Long Noncoding RNAs (LncRNAs)}

Long noncoding RNAs are long (>200 nucleotides) transcripts with no or restricted ability to encode proteins. They regulate various biological processes, such as transcription, splicing, translation, and function as molecular sponges for miRNAs [62]. Long noncoding RNAs are highly stable and circulate in body fluids, and their plasma levels were reportedly correlated with tumor tissue levels. Altered lncRNAs could be used to detect early-stage cancer and to predict prognosis, risk of metastasis, and recurrence $[63,64]$. Currently, $>56,000$ human lncRNAs have been recognized, and various lncRNAs have been dysregulated in GC $[65,66]$.

Various lncRNAs that are highly expressed in GC tissues have been analyzed as GC biomarkers [67] (Figure 2). Expression of plasmacytoma variant translocation 1 (PVT1) in GC tissues discriminated GC from non-GCs with an AUC of 0.728 , sensitivity of $80 \%$, and specificity of $60 \%$. PVT1 levels in gastric juice (GJ) were higher in GCs than that in non-GCs [68]. Highly upregulated in liver cancer (HULC) lncRNA is involved in gastric tumorigenesis. Overexpression of HULC lncRNA in GC cell lines enhanced the growth and invasion, whereas it suppressed apoptosis and induced autophagy. The epithelial-mesenchymal transition (EMT) phenotype was reversed by HULC silencing [69]. The plasma HULC and ZNFX1-AS1 levels were higher in GCs than that in non-GCs. The HULC levels discriminated GCs from non-GCs with an AUC of 0.65 , sensitivity of $58 \%$, and specificity of $80 \%$. Levels of ZNFX1-AS1 discriminated GCs from non-GCs with an AUC of 0.85 , sensitivity of $84 \%$, and specificity of $68 \%$ [70]. Plasma AA174084 levels significantly decreased in GCs postoperatively and were related to the depth of invasion and lymph node metastasis [71].

Long noncoding RNA H19 reportedly enhances GC cell growth and suppresses apoptosis [72]. Plasma H19 levels were higher in GCs than that in non-GCs [73-75] and discriminated between early-stage GCs and non-GCs with an AUC of 0.877 , sensitivity of $86 \%$, and specificity of $80 \%$ [73]. In addition, plasma $\mathrm{H} 19$ levels were lower in patients with GC postoperatively than preoperatively [73]. Therefore, the plasma H19 level could be a biomarker for the detection of early-stage GC. Plasma levels of long intergenic nonprotein-coding RNA 152 (LINC00152) were higher in GCs than those in 
non-GCs, and levels were higher in patients with GC postoperatively than preoperatively [76]. One of the possible mechanisms for its stability in the blood is thought to be protection by exosomes [76].

The levels of plasma gastric cancer associated transcript 2 (GACAT2) were higher in patients with GC than in non-GC controls, as well as in preoperative than that in postoperative samples. Relative changes in GACAT2 levels postoperatively were related to perineural invasion and to the lymph node and distal metastasis [77]. Plasma GACAT2 levels discriminated between GC and non-GC groups with an AUC of 0.622 , sensitivity of $87 \%$, and specificity of $28 \%$ [77]. Human urothelial carcinoma-associated 1 (UCA1) is involved in gastric tumorigenesis and is increased in patients with GC [78]. Hox transcript antisense intergenic RNA (HOTAIR) is involved in gastric tumorigenesis [79], and it reportedly enhances GC cell growth and suppresses apoptosis [70]. Moreover, enhanced HOTAIR expression was related to higher grades, metastasis, and advanced tumor stages. Plasma HOTAIR levels were higher in GCs than in non-GCs [79].

Genome-wide lncRNA microarray profiling identified a panel of five plasma lncRNAs (AOC4P, BANCR, CCAT2, LINC00857, and TINCR) that distinguished GCs from non-GCs. The IncRNA-based index was significantly diminished at 14 days postoperatively, showing its potential for monitoring tumor dynamics [80]. Similarly, a panel of three serum IncRNAs (PTENP1, CUDR, and LSINCT-5) reportedly distinguished early GC from non-GC with AUCs of 0.920 and 0.829 for the two sets of samples [81]. Additional analyses of lncRNAs are necessary to further support their clinical application.

\section{Circular RNAs (CircRNAs)}

Circular RNA is a noncoding RNA that forms a closed loop lacking $5^{\prime}$ and $3^{\prime}$ ends [82]. Circular RNAs are generated from introns or exons through loop introns or reverse splicing. The most common type is the exonic type. Circular RNAs are also generated from nonlinearly reverse spliced exon transcripts from pre-mRNA [83], including one or more exon loops and exon-intron hybrid loops (EIcircRNA). The intron also circularizes and creates circRNAs (ciRNAs).

Circular RNAs regulate gene expression via interactions with miRNAs [84]. Altered circRNAs are related to tumorigenesis, including GC [85]. Altered circRNA-miRNA-mRNA interactions are also implicated in GC. Various up- or downregulated circRNAs have been reported in GC tissues [86]. Because of their abundance, stability, tissue-specific expression, and broad circulation in diverse body fluids and exosomes, circRNAs could be new diagnostic biomarkers and GC therapeutic targets [87]. CircRNAs derived from exosomes (ex-circRNAs) could be a new diagnostic and/or prognostic marker.

Altered circRNA levels in body fluids have been reported to be comparable to those in tumor tissues and are considered possible biomarkers (Figure 2). Plasma hsa_circ_0000520 levels showed a better diagnostic accuracy than tissue levels. The AUC, sensitivity, and specificity of plasma hsa_circ_0000520 were $0.897,82 \%$, and $84 \%$, respectively, which were higher than those of the tissue levels $(0.613,54 \%$, and $86 \%$, respectively) [88]. Plasma hsa_circ_002059 and hsa_circ_0000190 levels could be diagnostic biomarkers for GC $[85,89]$. Other circRNAs, such as hsa_circ_00000181, hsa_circ_0001017, and hsa_circ_0061276, could be prognostic biomarkers for GC, with high sensitivity and specificity $[90,91]$. Although circRNAs can be considered as potential GC biomarkers, their usefulness requires further validation using large cohorts.

\section{Extracellular Vesicles (EVs)}

Extracellular vesicles are membrane-encased structures released from various cells [92,93]. They include exosomes, microvesicles, and apoptotic bodies and are classified into three major molecules according to particle size and biogenesis processes. Exosomes are $30-200 \mathrm{~nm}$ in size and are generated as intraluminal vesicles inside the lumen of multivesicular bodies. Microvesicles are $100-1000 \mathrm{~nm}$ in size and are generated when the cellular membrane is partly pinched off and directly discharged from originating cells. The apoptotic body is $500-2000 \mathrm{~nm}$ in size and is generated in the late phase of apoptosis. Plasma cfDNA is derived from cells that undergo necrosis or apoptosis, which might not reflect viable tumor cells. Conversely, exosomal nucleic acids (exoNAs), including DNAs 
and RNAs, are actively released from viable tumor cells and, therefore, could better reflect tumor dynamics (Figure 5) [94]. Moreover, exosomes can protect nucleic acids from degradation [95-98].

Cancer-related EVs play important roles in creating advantageous microenvironments for tumor cells through the interaction with diverse neighboring or distant cells. Extracellular vesicles stimulate EMT, angiogenesis, and immunosuppression through the transportation of functional molecules, such as nucleic acids, metabolites, and proteins. Extracellular vesicles also transfer cancer-related antigens to antigen-presenting cells. As EV cargoes derived from tumors hold biomolecular characteristics of their sources and tumor cells dynamically secrete EVs into body fluids, EVs are thought to be potentially promising resources for the identification of biomarkers.

Extracellular vesicles hold molecular cargoes that are protected from degradation in body fluids $[99,100]$. Cell-free DNAs are usually detected as short fragments $(<100 \mathrm{bp})$ because they are severely degraded in the blood [100]. Conversely, DNA fragments (100 bp to $17 \mathrm{~kb}$ ) in EVs represent a broader range of molecular information that could be detected in EV-DNAs [101]. Extracellular vesicle cargoes directly reflect the properties of their sources. For instance, BRCA2, NOTCH1, TP53, and KRAS gene mutations were detectable in EVs from patients with pancreatic and ampullary cancer [102]. Mutations of KRAS were detected in exoDNA in patients with early-stage pancreatic cancer [103]. In lung cancer, driver mutations were detectable in exoDNA more sensitively than those in cfDNA [104]. Cancer-related EVs also contain tumor-specific protein cargoes, suggesting that EVs can be considered as new diagnostic cancer biomarkers.

\section{Analysis of Gastric Juices/Washes}

\subsection{Gastric Juice (GJ)-Based Biomarkers}

Gastric juice could be a good biomarker source for GC, as it is directly secreted from cells without elimination by the liver [105]. Altered expression levels of oncomiRs (miR-421, miR-21, and miR-106a) and tumor suppressor miRNAs (miR-129 and miR-133a) have been reported in GJ samples from patients with GC than those from without GC (Figure 6). These GJ miRs are potential biomarkers for the detection of GC. As a possible mechanism underlying the decreased and increased oncomir levels in GJ and tissue/serum/plasma, respectively, GC cells may diminish the export of oncogenic miRs into GJ and enhance their release into the extracellular environment [106]. Thus, miRNA alteration in GJ could represent an alternative for the detection of GC via biopsy.

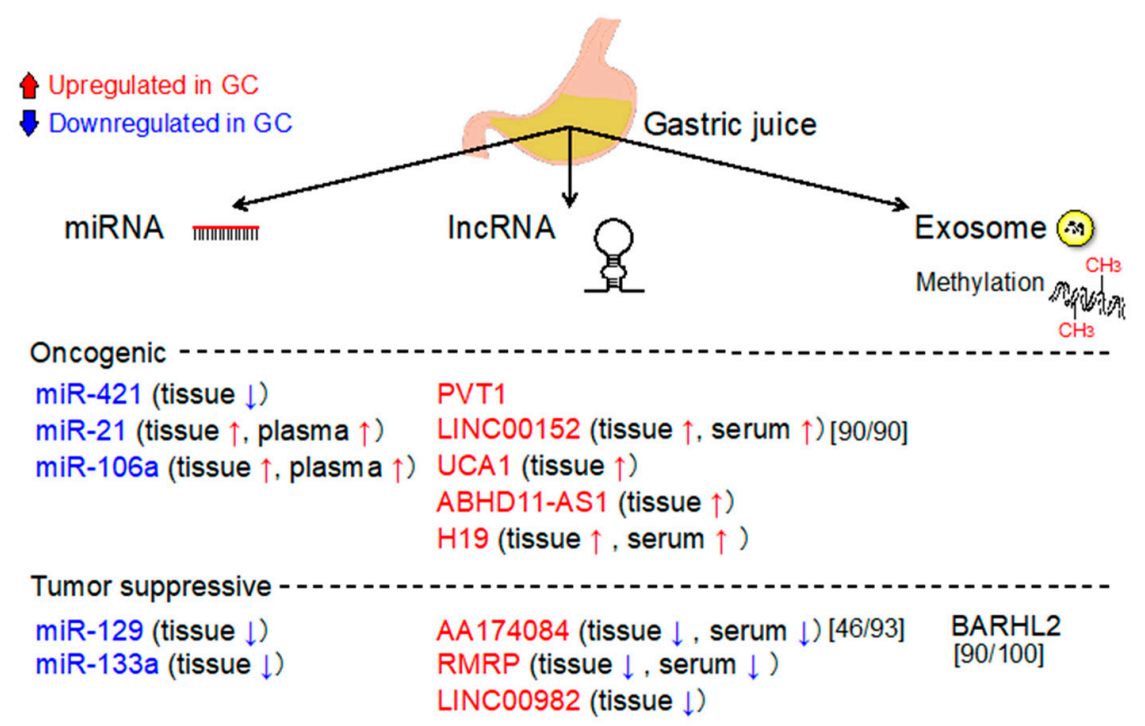

Figure 6. Gastric juice (GJ)-based molecular targets potentially considered as diagnostic biomarkers for GC. Upregulated (in red) and downregulated (in blue) markers are shown. Sensitivity and specificity are shown in square brackets. 
With regard to lncRNAs, the GJ AA174084 levels were higher in GCs than that in non-GCs [69]. Gastric juice AA174084 levels discriminated between GC and non-GC groups with an AUC of 0.848, sensitivity of $46 \%$, and specificity of $93 \%$. The AUC for GJ was higher than that for the tissue level (0.676). Similarly, LINC00152 discriminated GCs from non-GCs with an AUC of 0.645, sensitivity of 90\%, and specificity of 90\% [107]. Gastric juice PVT1 levels were significantly higher in GCs than in non-GCs, suggesting that PVT1 could be a useful biomarker for the early detection of GC [71]. Gastric juice ABHD11-AS levels were higher in patients with GC and were related to clinicopathological characteristics [108]. More importantly, the PPR for early GC was $71 \%$.

\subsection{DNA Methylation Analysis Using Gastric Washes (GWs)}

Since abundant mucosal cells could be obtained in GJ, DNA biomarkers using GJ were a potential method to detect GC. However, using GJ as a DNA biomarker has been unfeasible, as DNA is easily degraded due to gastric acidity. Thus, GWs are an alternative source for the detection of DNA alterations (Figure 7). A novel method for the detection of GC using GW DNA methylation analysis has been developed [109]. DNA methylation levels of MINT25 and GDNF were the most sensitive markers for GCs at the early stage, whereas methylation levels of MLF1 and PRDM5 were markers for a field defect in the stomach. The methylation levels in GWs were closely correlated with those in tumor biopsy samples. Moreover, MINT25 methylation in GW discriminated GC from non-GC with an AUC of 0.961 , sensitivity of $90 \%$, and specificity of $96 \%$, suggesting that it is a potentially sensitive and specific biomarker for the detection of GC.

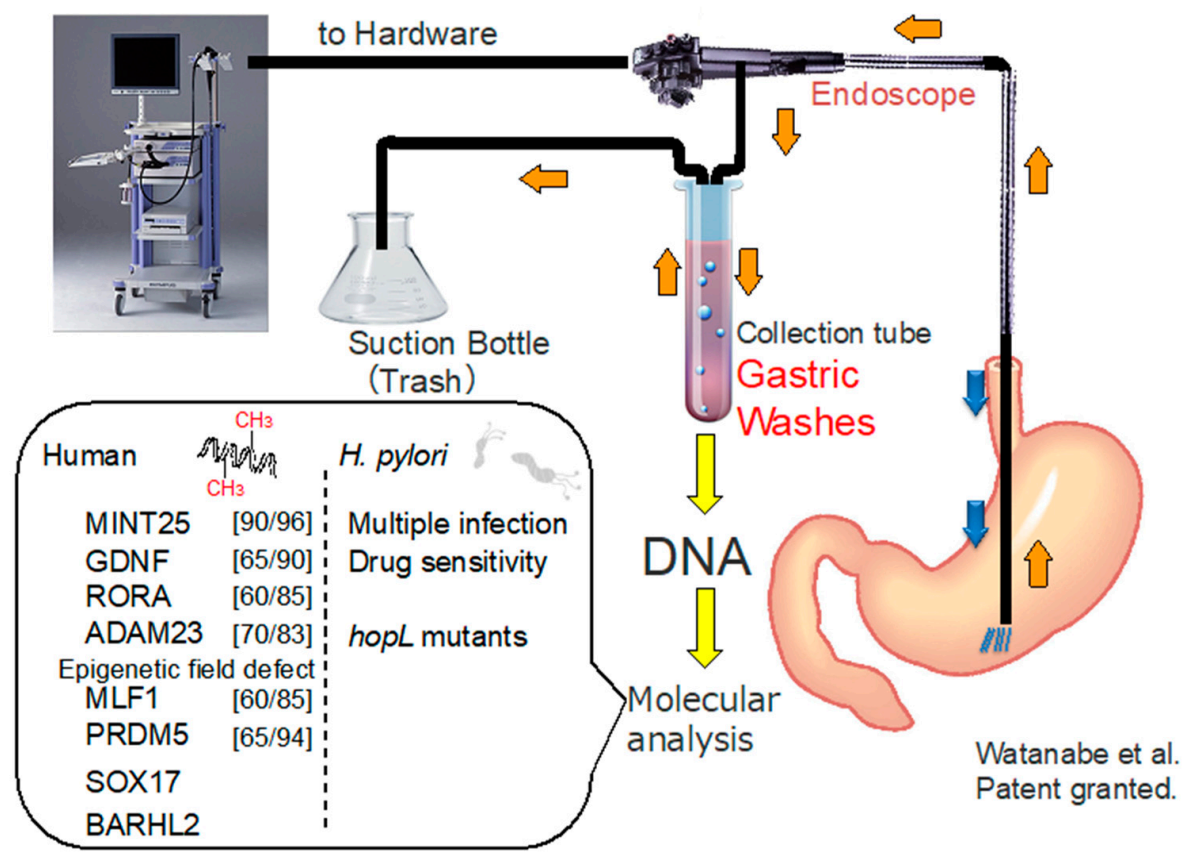

Figure 7. Gastric wash (GW)-based molecules with the potential as diagnostic biomarkers for GC. Sensitivity and specificity are shown in square brackets.

Although endoscopic therapy is generally used for GC at the early stage, predictive markers for residual cancer and/or recurrence after an endoscopic resection are necessary. Gastric wash DNA-based methylation analysis of Sox17 has been shown to be helpful for an early diagnosis of recurrence after an endoscopic treatment in patients with GC [110].

\subsection{Gastric Wash or Gastric Juice Exosomal DNA-Based Methylation Analysis of BARHL2}

Increased methylation levels of BARHL2 were detected in GW-derived DNA in patients with early GC before endoscopic therapy, whereas methylation levels were considerably reduced, following 
a curative endoscopic therapy. These results indicate that BARHL2 methylation could be helpful for the diagnosis of residual cancer after an endoscopic resection and potentially prediction of cancer recurrence [111]. Moreover, BARHL2 methylation in GJ-derived exoDNAs discriminated GC from non-GC with an AUC of 0.923 , sensitivity of $90 \%$, and specificity of $100 \%$. Therefore, GW or GJ exoDNA-based methylation analysis of BARH2 could be a promising biomarker for the early detection of GC.

\subsection{Analysis of Helicobacter pylori Genotypes Using GWs}

H. pylori is an important factor in the occurrence of GC. Eradication of $H$. pylori significantly reduces the occurrences of GC. The effectiveness of GW-based analysis of drug resistance in $H$. pylori has been shown [112]. Moreover, a quantitative pyrosequencing analysis using GWs was developed to evaluate the diversity and abundance of $H$. pylori genotypes [113]. These results obtained using GWs were comparable to those obtained using biopsy samples. Moreover, GW-based quantitative pyrosequencing revealed that $H$. pylori mutant strains were enriched after an eradication therapy [114]. This approach could be useful to analyze antibiotic resistance in $H$. pylori and to evaluate the potential risk of GC. Recently, GC-related genetic variants of H. pylori strains were determined using GW-based whole genome analysis with a single-molecule real-time technology. These results suggest that the hopL variant is related with the GC development and could be a genetic biomarker of $H$. pylori virulence and risk of GC [115].

\section{Ongoing Studies Concerning the Early Molecular Detection of GC}

Ongoing studies (prospective observational or retrospective) concerning the early molecular detection of GC are summarized (Table S1). With regard to GW, we have done a multicenter prospective cohort study with $>400$ patients with early GC who had undergone endoscopic resection to determine whether GW-based DNA methylation levels could predict the risk of developing metachronous GCs. Data analysis of this study is underway.

\section{Conclusions}

Recent progress in the biomolecular characterization of GC has delivered potentially novel clinical diagnostic and/or therapeutic approaches. Molecular analyses based on noninvasively obtained body fluids, including GJ/GW, are potentially useful for the early detection of GC. However, population studies or studies on early-stage GC to determine its usefulness as an early detection screening tool are still limited. Although validation using independent cohorts in prospective studies is necessary, body-fluids-based molecular testing could be a new noninvasive diagnostic biomarker with high accuracy for the early detection of GC and may be incorporated into GC clinical settings in the near future.

Supplementary Materials: The following are available online at http://www.mdpi.com/2072-6694/12/10/2880/s1, Table S1: Ongoing studies concerning the early molecular detection of GC.

Funding: This research was funded by JSPS KAKENHI Grant Numbers JP16K09295 (to Y. Watanabe) and JP19H03521 (to H. Yamamoto).

Conflicts of Interest: The authors declare no conflict of interest.

\section{References}

1. Ferlay, J.; Colombet, M.; Soerjomataram, I.; Mathers, C.; Parkin, D.M.; Piñeros, M.; Znaor, A.; Bray, F. Estimating the global cancer incidence and mortality in 2018: GLOBOCAN sources and methods. Int. J. Cancer 2019, 144, 1941-1953. [CrossRef]

2. Wadhwa, R.; Song, S.; Lee, J.S.; Yao, Y.; Wei, Q.; Ajani, J.A. Gastric cancer-molecular and clinical dimensions. Nat. Rev. Clin. Oncol. 2013, 10, 643-655. [CrossRef] 
3. Salati, M.; Orsi, G.; Smyth, E.; Aprile, G.; Beretta, G.; de Vita, F.; di Bartolomeo, M.; Fanotto, V.; Lonardi, S.; Morano, F.; et al. Gastric cancer: Translating novels concepts into clinical practice. Cancer Treat. Rev. 2019, 79, 101889. [CrossRef]

4. Figueiredo, C.; Garcia-Gonzalez, M.A.; Machado, J.C. Molecular pathogenesis of gastric cancer. Helicobacter 2013, 18 (Suppl. 1), 28-33. [CrossRef] [PubMed]

5. Conteduca, V.; Sansonno, D.; Lauletta, G.; Russi, S.; Ingravallo, G.; Dammacco, F.H. Pylori infection and gastric cancer: State of the art. Int. J. Oncol. 2013, 42, 5-18. [CrossRef] [PubMed]

6. Levy, I.; Gralnek, I.M. Complications of diagnostic colonoscopy, upper endoscopy, and enteroscopy. Best Pract. Res. Clin. Gastroenterol. 2016, 30, 705-718. [CrossRef] [PubMed]

7. Zhang, X.; Li, M.; Chen, S.; Hu, J.; Guo, Q.; Liu, R.; Zheng, H.; Jin, Z.; Yuan, Y.; Xi, Y.; et al. Endoscopic screening in Asian countries is associated with reduced gastric cancer mortality: A meta-analysis and systematic review. Gastroenterology 2018, 155, 347-354. [CrossRef]

8. Yamamoto, E.; Suzuki, H.; Takamaru, H.; Yamamoto, H.; Toyota, M.; Shinomura, Y. Role of DNA methylation in the development of diffuse-type gastric cancer. Digestion 2011, 83, 241-249. [CrossRef]

9. Baker, A.M.; Graham, T.A.; Wright, N.A. Pre-tumour clones, periodic selection and clonal interference in the origin and progression of gastrointestinal cancer: Potential for biomarker development. J. Pathol. 2013, 229, 502-514. [CrossRef]

10. Yamamoto, H.; Watanabe, Y.; Maehata, T.; Morita, R.; Yoshida, Y.; Oikawa, R.; Ishigooka, S.; Ozawa, S.; Matsuo, Y.; Hosoya, K.; et al. An updated review of gastric cancer in the next-generation sequencing era: Insights from bench to bedside and vice versa. World J. Gastroenterol. 2014, 20, 3927-3937. [CrossRef]

11. Matsuoka, T.; Yashiro, M. Biomarkers of gastric cancer: Current topics and future perspective. World J. Gastroenterol. 2018, 24, 2818-2832. [CrossRef] [PubMed]

12. Necula, L.; Matei, L.; Dragu, D.; Neagu, A.I.; Mambet, C.; Nedeianu, S.; Bleotu, C.; Diaconu, C.C.; Chivu-Economescu, M. Recent advances in gastric cancer early diagnosis. World J. Gastroenterol. 2019, 25, 2029-2044. [CrossRef] [PubMed]

13. Matsuoka, T.; Yashiro, M. Precision medicine for gastrointestinal cancer: Recent progress and future perspective. World J. Gastrointest. Oncol. 2020, 12, 1-20. [CrossRef] [PubMed]

14. Azad, N.; Zahnow, C.A.; Rudin, C.M.; Baylin, S.B. The future of epigenetic therapy in solid tumours-Lessons from the past. Nat. Rev. Clin. Oncol. 2013, 10, 256-266. [CrossRef] [PubMed]

15. Zouridis, H.; Deng, N.; Ivanova, T.; Zhu, Y.; Wong, B.; Huang, D.; Wu, Y.H.; Wu, Y.; Tan, I.B.; Liem, N. Methylation subtypes and large-scale epigenetic alterations in gastric cancer. Sci. Transl. Med. 2012, 4, 156ra140. [CrossRef]

16. Gigek, C.O.; Chen, E.S.; Calcagno, D.Q.; Wisnieski, F.; Burbano, R.R.; Smith, M.A. Epigenetic mechanisms in gastric cancer. Epigenomics 2012, 4, 279-294. [CrossRef]

17. Qu, Y.; Dang, S.; Hou, P. Gene methylation in gastric cancer. Clin. Chim. Acta 2013, 424, 53-65. [CrossRef]

18. Calcagno, D.Q.; Gigek, C.O.; Chen, E.S.; Burbano, R.R.; Smith, M.D.A.C. DNA and histone methylation in gastric carcinogenesis. World J. Gastroenterol. 2013, 19, 1182-1192. [CrossRef]

19. Otani, K.; Li, X.; Arakawa, T.; Chan, F.K.; Yu, J. Epigenetic-mediated tumor suppressor genes as diagnostic or prognostic biomarkers in gastric cancer. Expert Rev. Mol. Diagn. 2013, 13, 445-455. [CrossRef]

20. Cescon, D.W.; Bratman, S.V.; Chan, S.M.; Siu, L.L. Circulating tumor DNA and liquid biopsy in oncology. Nat. Cancer 2020, 1, 276-290. [CrossRef]

21. Mitchell, P.S.; Parkin, R.K.; Kroh, E.M.; Fritz, B.R.; Wyman, S.K.; Pogosova-Agadjanyan, E.L.; Peterson, A.; Noteboom, J.; O'Briant, K.C.; Allen, A. Circulating microRNAs as stable blood-based markers for cancer detection. Proc. Natl. Acad. Sci. USA 2008, 105, 10513-10518. [CrossRef] [PubMed]

22. Melo, S.A.; Esteller, M. Dysregulation of microRNAs in cancer: Playing with fire. FEBS Lett. 2011, 585, 2087-2099. [CrossRef] [PubMed]

23. Cortez, M.A.; Bueso-Ramos, C.; Ferdin, J.; Lopez-Berestein, G.; Sood, A.K.; Calin, G.A. MicroRNAs in body fluids-The mix of hormones and biomarkers. Nat. Rev. Clin. Oncol. 2011, 8, 467-477. [CrossRef] [PubMed]

24. Van Kouwenhove, M.; Kedde, M.; Agami, R. MicroRNA regulation by RNA-binding proteins and its implications for cancer. Nat. Rev. Cancer 2011, 11, 644-656. [CrossRef]

25. Lopez-Serra, P.; Esteller, M. DNA methylation-associated silencing of tumor-suppressor microRNAs in cancer. Oncogene 2012, 31, 1609-1622. [CrossRef] 
26. Ueda, T.; Volinia, S.; Okumura, H.; Shimizu, M.; Taccioli, C.; Rossi, S.; Alder, H.; Liu, C.G.; Oue, N.; Yasui, W. Relation between microRNA expression and progression and prognosis of gastric cancer: A microRNA expression analysis. Lancet Oncol. 2010, 11, 136-146. [CrossRef]

27. Albulescu, R.; Neagu, M.; Albulescu, L.; Tanase, C. Tissular and soluble miRNAs for diagnostic and therapy improvement in digestive tract cancers. Expert Rev. Mol. Diagn. 2011, 11, 101-120. [CrossRef]

28. Pan, H.W.; Li, S.C.; Tsai, K.W. MicroRNA dysregulation in gastric cancer. Curr. Pharm. Des. 2013, 19, 1273-1284.

29. Tong, F.; Cao, P.; Yin, Y.; Xia, S.; Lai, R.; Liu, S. MicroRNAs in gastric cancer: From benchtop to bedside. Dig. Dis. Sci. 2014, 59, 24-30. [CrossRef]

30. Stojanovic, J.; Tognetto, A.; Tiziano, D.F.; Leoncini, E.; Posteraro, B.; Pastorino, R.; Boccia, S. MicroRNAs expression profiles as diagnostic biomarkers of gastric cancer: A systematic literature review. Biomarkers 2019, 24, 110-119. [CrossRef]

31. Telonis, A.G.; Magee, R.; Loher, P.; Chervoneva, I.; Londin, E.; Rigoutsos, I. Knowledge about the presence or absence of miRNA isoforms (isomiRs) can successfully discriminate amongst 32 TCGA cancer types. Nucleic Acids Res. 2017, 45, 2973-2985. [CrossRef] [PubMed]

32. Link, A.; Kupcinskas, J. MicroRNAs as non-invasive diagnostic biomarkers for gastric cancer: Current insights and future perspectives. World J. Gastroenterol. 2018, 24, 3313-3329. [CrossRef] [PubMed]

33. Wu, J.; Li, G.; Wang, Z.; Yao, Y.; Chen, R.; Pu, X.; Wang, J. Circulating microRNA-21 is a potential diagnostic biomarker in gastric cancer. Dis. Markers 2015, 2015, 1-8. [CrossRef]

34. Tsai, M.M.; Wang, C.S.; Tsai, C.Y.; Huang, C.G.; Lee, K.F.; Huang, H.W.; Lin, Y.H.; Chi, H.C.; Kuo, L.M.; Lu, P.H.; et al. Circulating microRNA-196a/b are novel biomarkers associated with metastatic gastric cancer. Eur. J. Cancer 2016, 64, 137-148. [CrossRef] [PubMed]

35. Hung, P.S.; Chen, C.Y.; Chen, W.T.; Kuo, C.Y.; Fang, W.L.; Huang, K.H.; Chiu, P.C.; Lo, S.S. miR-376c promotes carcinogenesis and serves as a plasma marker for gastric carcinoma. PLoS ONE 2017, 12, e0177346. [CrossRef]

36. Hanke, M.; Hoefig, K.; Merz, H.; Feller, A.C.; Kausch, I.; Jocham, D.; Warnecke, J.M.; Sczakiel, G. A robust methodology to study urine microRNA as tumor marker: MicroRNA-126 and microRNA-182 are related to urinary bladder cancer. Urol. Oncol. 2010, 28, 655-661. [CrossRef]

37. Zhou, J.; Gong, G.; Tan, H.; Dai, F.; Zhu, X.; Chen, Y.; Wang, J.; Liu, Y.; Chen, P.; Wu, X.; et al. Urinary microRNA-30a-5p is a potential biomarker for ovarian serous adenocarcinoma. Oncol Rep. 2015, 33, 2915-2923. [CrossRef]

38. Zhu, C.; Ren, C.; Han, J.; Ding, Y.; Du, J.; Dai, N.; Dai, J.; Ma, H.; Hu, Z.; Shen, H.; et al. A five-microRNA panel in plasma was identified as potential biomarker for early detection of gastric cancer. Br. J. Cancer 2014, 110, 2291-2299. [CrossRef]

39. Huang, Z.; Zhu, D.; Wu, L.; He, M.; Zhou, X.; Zhang, L.; Zhang, H.; Wang, W.; Zhu, J.; Cheng, W.; et al. Six serum-based miRNAs as potential diagnostic biomarkers for gastric cancer. Cancer Epidemiol. Biomark. Prev. 2017, 26, 188-196. [CrossRef]

40. Nik Mohamed Kamal, N.N.; Shahidan, W.N. Non-exosomal and exosomal circulatory microRNAs: Which are more valid as biomarkers? Front. Pharmacol. 2020, 10, 1500. [CrossRef]

41. Arroyo, J.D.; Chevillet, J.R.; Kroh, E.M.; Ruf, I.K.; Pritchard, C.C.; Gibson, D.F.; Mitchell, P.S.; Bennett, C.F.; Pogosova-Agadjanyan, E.L.; Stirewalt, D.L.; et al. Argonaute2 complexes carry a population of circulating microRNAs independent of vesicles in human plasma. Proc. Natl. Acad. Sci. USA 2011, 108, 5003-5008. [CrossRef] [PubMed]

42. Wang, J.; Zhang, H.; Zhou, X.; Wang, T.; Zhang, J.Y.; Zhu, W.; Zhu, H.; Cheng, W. Five serum-based miRNAs were identified as potential diagnostic biomarkers in gastric cardia adenocarcinoma. Cancer Biomark. 2018, 23, 193-203. [CrossRef] [PubMed]

43. Wang, N.; Wang, L.; Yang, Y.; Gong, L.; Xiao, B.; Liu, X. A serum exosomal microRNA panel as a potential biomarker test for gastric cancer. Biochem. Biophys. Res. Commun. 2017, 493, 1322-1328. [CrossRef] [PubMed]

44. Ranjbar, R.; Hesari, A.; Ghasemi, F.; Sahebkar, A. Expression of microRNAs and IRAK1 pathway genes are altered in gastric cancer patients with Helicobacter pylori infection. J. Cell. Biochem. 2018, 119, 7570-7576. [CrossRef] [PubMed]

45. Ruggieri, V.; Russi, S.; Zoppoli, P.; La Rocca, F.; Angrisano, T.; Falco, G.; Calice, G.; Laurino, S. The role of microRNAs in the regulation of gastric cancer stem cells: A meta-analysis of the current status. J. Clin. Med. 2019, 8, 639. [CrossRef] [PubMed] 
46. Suzuki, H.; Yamamoto, E.; Nojima, M.; Kai, M.; Yamano, H.O.; Yoshikawa, K.; Kimura, T.; Kudo, T.; Harada, E.; Sugai, T.; et al. Methylation-associated silencing of microRNA-34b/c in gastric cancer and its involvement in an epigenetic field defect. Carcinogenesis 2010, 31, 2066-2073. [CrossRef] [PubMed]

47. Suzuki, R.; Yamamoto, E.; Nojima, M.; Maruyama, R.; Yamano, H.O.; Yoshikawa, K.; Kimura, T.; Harada, T.; Ashida, M.; Niinuma, T.; et al. Aberrant methylation of microRNA-34b/c is a predictive marker of metachronous gastric cancer risk. J. Gastroenterol. 2014, 49, 1135-1144. [CrossRef]

48. Pantel, K.; Alix-Panabières, C. Liquid biopsy in 2016: Circulating tumour cells and cell-free DNA in gastrointestinal cancer. Nat. Rev. Gastroenterol. Hepatol. 2017, 14, 73-74. [CrossRef]

49. Guimarães, C.T.U.; Martins, N.N.F.; Oliveira, K.C.D.S.; Almeida, C.M.; Pinheiro, T.M.; Gigek, C.O.; Cavalléro, S.R.D.A.; Assumpção, P.P.; Smith, M.A.C.; Burbano, R.R.; et al. Liquid biopsy provides new insights into gastric cancer. Oncotarget 2018, 9, 15144-15156.

50. Russi, S.; Calice, G.; Ruggieri, V.; Laurino, S.; La Rocca, F.; Amendola, E.; Lapadula, C.; Compare, D.; Nardone, G.; Musto, P.; et al. Gastric normal adjacent mucosa versus healthy and cancer tissues: Distinctive transcriptomic profiles and biological features. Cancers 2019, 11, 1248. [CrossRef]

51. Watanabe, T.; Okumura, T.; Hirano, K.; Yamaguchi, T.; Sekine, S.; Nagata, T.; Tsukada, K. Circulating tumor cells expressing cancer stem cell marker CD44 as a diagnostic biomarker in patients with gastric cancer. Oncol. Lett. 2017, 13, 281-288. [CrossRef] [PubMed]

52. Huong, P.T.; Gurshaney, S.; Binh, N.T.; Anh, P.G.; Nguyen, H.H.; Nguyen, X.T.; Pham-The, H.; Tran, P.-T.; Vu, K.T.; Duong, N.X.; et al. Emerging role of circulating tumor cells in gastric cancer. Cancers 2020, $12,695$. [CrossRef] [PubMed]

53. Tang, L.; Zhao, S.; Liu, W.; Parchim, N.F.; Huang, J.; Tang, Y.; Gan, P.; Zhong, M. Diagnostic accuracy of circulating tumor cells detection in gastric cancer: Systematic review and meta-analysis. BMC Cancer 2013, 13, 314. [CrossRef] [PubMed]

54. Neumann, M.H.D.; Bender, S.; Krahn, T.; Schlange, T. ctDNA and CTCs in liquid biopsy-Current status and where we need to progress. Comput. Struct. Biotechnol. J. 2018, 16, 190-195. [CrossRef] [PubMed]

55. Koldby, K.M.; Mortensen, M.B.; Detlefsen, S.; Pfeiffer, P.; Thomassen, M.; Kruse, T.A. Tumor-specific genetic aberrations in cell-free DNA of gastroesophageal cancer patients. J. Gastroenterol. 2019, 54, 108-121. [CrossRef] [PubMed]

56. Bettegowda, C.; Sausen, M.; Leary, R.J.; Kinde, I.; Wang, Y.; Agrawal, N.; Bartlett, B.R.; Wang, H.; Luber, B.; Alani, R.M.; et al. Detection of circulating tumor DNA in early- and late-stage human malignancies. Sci. Transl. Med. 2014, 6, 224ra24. [CrossRef] [PubMed]

57. Alix-Panabières, C.; Pantel, K. Clinical applications of circulating tumor cells and circulating tumor DNA as liquid biopsy. Cancer Discov. 2016, 6, 479-491. [CrossRef]

58. Sumbal, S.; Javed, A.; Afroze, B.; Zulfiqar, H.F.; Javed, F.; Noreen, S.; Ijaz, B. Circulating tumor DNA in blood: Future genomic biomarkers for cancer detection. Exp. Hematol. 2018, 65, 17-28. [CrossRef]

59. Cohen, J.D.; Li, L.; Wang, Y.; Thoburn, C.; Afsari, B.; Danilova, L.; Douville, C.; Javed, A.A.; Wong, F.; Mattox, A.; et al. Detection and localization of surgically resectable cancers with a multi-analyte blood test. Science 2018, 359, 926-930. [CrossRef]

60. Saini, A.; Pershad, Y.; Albadawi, H.; Kuo, M.; Alzubaidi, S.; Naidu, S.; Knuttinen, M.G.; Oklu, R. Liquid biopsy in gastrointestinal cancers. Diagnostics 2018, 8, 75. [CrossRef]

61. Shoda, K.; Ichikawa, D.; Fujita, Y.; Masuda, K.; Hiramoto, H.; Hamada, J.; Arita, T.; Konishi, H.; Kosuga, T.; Komatsu, S.; et al. Clinical utility of circulating cell-free Epstein-Barr virus DNA in patients with gastric cancer. Oncotarget 2017, 8, 28796-28804. [CrossRef] [PubMed]

62. Wang, J.; Song, Y.-X.; Wang, Z. Non-coding RNAs in gastric cancer. Gene 2015, 560, 1-8. [CrossRef] [PubMed]

63. Shi, T.; Gao, G.; Cao, Y. Long noncoding RNAs as novel biomarkers have a promising future in cancer diagnostics. Dis. Markers 2016, 2016, 1-10. [CrossRef] [PubMed]

64. Bolha, L.; Ravnik-Glavač, M.; Glavač, D. Long noncoding RNAs as biomarkers in cancer. Dis. Markers 2017, 2017, 1-14. [CrossRef] [PubMed]

65. Song, H.; Sun, W.; Ye, G.; Ding, X.; Liu, Z.; Zhang, S.; Xia, T.; Xiao, B.-X.; Xi, Y.; Guo, J. Long non-coding RNA expression profile in human gastric cancer and its clinical significances. J. Transl. Med. 2013, 11, 225. [CrossRef]

66. Fang, X.-Y.; Pan, H.-F.; Leng, R.-X.; Ye, D.-Q. Long noncoding RNAs: Novel insights into gastric cancer. Cancer Lett. 2015, 356, 357-366. [CrossRef] 
67. Wang, J.; Sun, J.; Wang, J.; Song, Y.; Gao, P.; Shi, J.; Chen, P.; Wang, Z. Long noncoding RNAs in gastric cancer: Functions and clinical applications. Onco Targets Ther. 2016, 9, 681-697. [CrossRef]

68. Yuan, C.L.; Li, H.; Zhu, L.; Liu, Z.; Zhou, J.; Shu, Y. Aberrant expression of long noncoding RNA PVT1 and its diagnostic and prognostic significance in patients with gastric cancer. Neoplasma 2016, 63, 442-449. [CrossRef]

69. Zhao, Y.; Guo, Q.; Chen, J.; Hu, J.; Wang, S.; Sun, Y. Role of long non-coding RNA HULC in cell proliferation, apoptosis and tumor metastasis of gastric cancer: A clinical and in vitro investigation. Oncol. Rep. 2014, 31, 358-364. [CrossRef]

70. Xian, H.P.; Zhuo, Z.L.; Sun, Y.J.; Liang, B.; Zhao, X.T. Circulating long non-coding RNAs HULC and ZNFX1-AS1 are potential biomarkers in patients with gastric cancer. Oncol. Lett. 2018, 16, 4689-4698. [CrossRef]

71. Shao, Y.; Ye, M.; Jiang, X.; Sun, W.; Ding, X.; Liu, Z.; Ye, G.; Zhang, X.; Xiao, B.; Guo, J. Gastric juice long noncoding RNA used as a tumor marker for screening gastric cancer. Cancer 2014, 120, 3320-3328. [CrossRef] [PubMed]

72. Arita, T.; Ichikawa, D.; Konishi, H.; Komatsu, S.; Shiozaki, A.; Shoda, K.; Kawaguchi, T.; Hirajima, S.; Nagata, H.; Kubota, T.; et al. Circulating long non-coding RNAs in plasma of patients with gastric cancer. Anticancer Res. 2013, 33, 3185-3193. [PubMed]

73. Zhou, X.; Yin, C.; Dang, Y.; Ye, F.; Zhang, G. Identification of the long non-coding RNA H19 in plasma as a novel biomarker for diagnosis of gastric cancer. Sci. Rep. 2015, 5, 11516. [CrossRef] [PubMed]

74. Hashad, D.; Elbanna, A.; Ibrahim, A.; Khedr, G. Evaluation of the role of circulating long non-coding RNA H19 as a promising novel biomarker in plasma of patients with gastric cancer. J. Clin. Lab. Anal. 2016, 30, 1100-1105. [CrossRef]

75. Yörüker, E.E.; Keskin, M.; Kulle, C.B.; Holdenrieder, S.; Gezer, U. Diagnostic and prognostic value of circulating lncRNA H19 in gastric cancer. Biomed. Rep. 2018, 9, 181-186.

76. Li, Q.; Shao, Y.; Zhang, X.; Zheng, T.; Miao, M.; Qin, L.; Wang, B.; Ye, G.; Xiao, B.; Guo, J. Plasma long noncoding RNA protected by exosomes as a potential stable biomarker for gastric cancer. Tumor Biol. 2015, 36, 2007-2012. [CrossRef]

77. Tan, L.; Yang, Y.; Shao, Y.; Zhang, H.; Guo, J. Plasma lncRNA-GACAT2 is a valuable marker for the screening of gastric cancer. Oncol. Lett. 2016, 12, 4845-4849. [CrossRef]

78. Gao, J.; Cao, R.; Mu, H. Long non-coding RNA UCA1 may be a novel diagnostic and predictive biomarker in plasma for early gastric cancer. Int. J. Clin. Exp. Pathol. 2015, 8, 12936-12942.

79. Elsayed, E.T.; Salem, P.E.; Darwish, A.M.; Fayed, H.M. Plasma long non-coding RNA HOTAIR as a potential biomarker for gastric cancer. Int. J. Biol. Markers 2018, 33, 528-533. [CrossRef]

80. Zhang, K.; Shi, H.; Xi, H.; Wu, X.; Cui, J.; Gao, Y.; Liang, W.; Hu, C.; Liu, Y.; Li, J.; et al. Genome-wide lncRNA microarray profiling identifies novel circulating lncRNAs for detection of gastric cancer. Theranostics 2017, 7, 213-227. [CrossRef]

81. Dong, L.; Qi, P.; Xu, M.-D.; Ni, S.-J.; Huang, D.; Xu, Q.-H.; Weng, W.; Tan, C.; Sheng, W.; Zhou, X.-Y.; et al. Circulating CUDR, LSINCT-5 and PTENP1 long noncoding RNAs in sera distinguish patients with gastric cancer from healthy controls. Int. J. Cancer 2015, 137, 1128-1135. [CrossRef] [PubMed]

82. Memczak, S.; Jens, M.; Elefsinioti, A.; Torti, F.; Krueger, J.; Rybak, A.; Maier, L.; Mackowiak, S.D.; Gregersen, L.H.; Munschauer, M.; et al. Circular RNAs are a large class of animal RNAs with regulatory potency. Nature 2013, 495, 333-338. [CrossRef] [PubMed]

83. Zhang, H.; Shen, Y.; Li, Z.; Ruan, Y.; Li, T.; Xiao, B.; Sun, W. The biogenesis and biological functions of circular RNAs and their molecular diagnostic values in cancers. J. Clin. Lab. Anal. 2020, 34, e23049. [CrossRef]

84. Chen, L.L. The biogenesis and emerging roles of circular RNAs. Nat. Rev. Mol. Cell. Biol. 2016, 17, $205-211$. [CrossRef] [PubMed]

85. Li, P.; Chen, S.; Chen, H.; Mo, X.; Li, T.; Shao, Y.; Xiao, B.; Guo, J. Using circular RNA as a novel type of biomarker in the screening of gastric cancer. Clin. Chim. Acta. 2015, 444, 132-136. [CrossRef]

86. Vidal, A.F.; Ribeiro-Dos-Santos, A.M.; Sandoval, T.V.; De Magalhães, L.L.; Pinto, P.; Anaissi, A.K.M.; Demachki, S.; De Assumpção, P.P.; Dos Santos, S.E.B.; Ribeiro-Dos-Santos, A. The comprehensive expression analysis of circular RNAs in gastric cancer and its association with field cancerization. Sci. Rep. 2017, 7, 14551. [CrossRef] 
87. Jiang, F.; Hong, F.; Shah, M.W.; Shen, X. Circular RNAs as diagnostic biomarkers in gastric cancer: A meta-analysis review. Pathol. Res. Pract. 2019, 215, 152419. [CrossRef]

88. Sun, H.; Tang, W.; Rong, D.; Jin, H.; Fu, K.; Zhang, W.; Liu, Z.; Cao, H.; Cao, X. Hsa_circ_0000520, a potential new circular RNA biomarker, is involved in gastric carcinoma. Cancer Biomark. 2018, 21, 299-306. [CrossRef]

89. Chen, S.; Li, T.; Zhao, Q.; Xiao, B.; Guo, J. Using circular RNA hsa_circ_0000190 as a new biomarker in the diagnosis of gastric cancer. Clin. Chim. Acta 2017, 466, 167-171. [CrossRef]

90. Zhao, Q.; Chen, S.; Li, T.; Xiao, B.; Zhang, X. Clinical values of circular RNA 0000181 in the screening of gastric cancer. J. Clin. Lab. Anal. 2018, 32, e22333. [CrossRef]

91. Li, T.; Shao, Y.; Fu, L.; Xie, Y.; Zhu, L.; Sun, W.; Yu, R.; Xiao, B.; Guo, J. Plasma circular RNA profiling of patients with gastric cancer and their droplet digital RT-PCR detection. J. Mol. Med. 2018, 96, 85-96. [CrossRef] [PubMed]

92. Fu, M.; Gu, J.; Jiang, P.; Qian, H.; Xu, W.; Zhang, X. Exosomes in gastric cancer: Roles, mechanisms, and applications. Mol. Cancer 2019, 18, 41. [CrossRef] [PubMed]

93. Huang, T.; Song, C.; Zheng, L.; Xia, L.; Li, Y.; Zhou, Y. The roles of extracellular vesicles in gastric cancer development, microenvironment, anti-cancer drug resistance, and therapy. Mol. Cancer 2019, 18, 62. [CrossRef] [PubMed]

94. Kahroba, H.; Hejazi, M.S.; Samadi, N. Exosomes: From carcinogenesis and metastasis to diagnosis and treatment of gastric cancer. Cell. Mol. Life Sci. 2019, 76, 1747-1758. [CrossRef] [PubMed]

95. Valadi, H.; Ekstrom, K.; Bossios, A.; Sjostrand, M.; Lee, J.J.; Lotvall, J.O. Exosome-mediated transfer of mRNAs and microRNAs is a novel mechanism of genetic exchange between cells. Nat. Cell Biol. 2007, 9, 654-659. [CrossRef]

96. Skog, J.; Würdinger, T.; van Rijn, S.; Meijer, D.H.; Gainche, L.; Sena-Esteves, M.; Curry, W.T., Jr.; Carter, B.S.; Krichevsky, A.M.; Breakefield, X.O. Glioblastoma microvesicles transport RNA and proteins that promote tumour growth and provide diagnostic biomarkers. Nat. Cell Biol. 2008, 10, 1470-1476. [CrossRef]

97. Pegtel, D.M.; Cosmopoulos, K.; Thorley-Lawson, D.A.; Van Eijndhoven, M.A.J.; Hopmans, E.S.; Lindenberg, J.L.; De Gruijl, T.D.; Würdinger, T.; Middeldorp, J.M. Functional delivery of viral miRNAs via exosomes. Proc. Natl. Acad. Sci. USA 2010, 107, 6328-6333. [CrossRef]

98. Cheng, L.; Sharples, R.A.; Scicluna, B.J.; Hill, A.F. Exosomes provide a protective and enriched source of miRNA for biomarker profiling compared to intracellular and cell-free blood. J. Extracell. Vesicles 2014, 3, 3. [CrossRef]

99. Huang, X.; Yuan, T.; Tschannen, M.; Sun, Z.; Jacob, H.; Du, M.; Liang, M.; Dittmar, R.L.; Liu, Y.; Liang, M.; et al. Characterization of human plasma-derived exosomal RNAs by deep sequencing. BMC Genom. 2013, 14, 1-14. [CrossRef]

100. Ridder, K.; Keller, S.; Dams, M.; Rupp, A.K.; Schlaudraff, J.; del Turco, D.; Starmann, J.; Jadranka Macas, J.; Karpova, D.; Devraj, K.; et al. Extracellular vesicle-mediated transfer of genetic information between the hematopoietic system and the brain in response to inflammation. PLoS Biol. 2014, 12, e1001874. [CrossRef]

101. Kalluri, R.; LeBleu, V.S. Discovery of double-stranded genomic DNA in circulating exosomes. Cold Spring Harb. Symp. Quant. Biol. 2016, 81, 275-280. [CrossRef] [PubMed]

102. Lucas, F.A.S.; Allenson, K.; Bernard, V.; Castillo, J.; Kim, D.U.; Ellis, K.; Ehli, E.A.; Davies, G.E.; Petersen, J.L.; Li, D.; et al. Minimally invasive genomic and transcriptomic profiling of visceral cancers by next-generation sequencing of circulating exosomes. Ann. Oncol. 2016, 27, 635-641. [CrossRef] [PubMed]

103. Allenson, K.; Castillo, J.; Lucas, F.A.S.; Scelo, G.; Kim, D.U.; Bernard, V.; Davis, G.; Kumar, T.; Katz, M.; Overman, M.J.; et al. High prevalence of mutant KRAS in circulating exosome-derived DNA from early-stage pancreatic cancer patients. Ann. Oncol. 2017, 28, 741-747. [CrossRef] [PubMed]

104. Möhrmann, L.; Huang, H.J.; Hong, D.S.; Tsimberidou, A.M.; Fu, S.; Piha-Paul, S.A.; Subbiah, V.; Karp, D.D.; Naing, A.; Krug, A.; et al. Liquid biopsies using plasma exosomal nucleic acids and plasma cell-free DNA compared with clinical outcomes of patients with advanced cancers. Clin. Cancer Res. 2018, 24, 181-188. [CrossRef]

105. Virgilio, E.; Giarnieri, E.; Giovagnoli, M.R.; Montagnini, M.; Proietti, A.; D’Urso, R.; Mercantini, P.; Balducci, G.; Cavallini, M. Gastric juice microRNAs as potential biomarkers for screening gastric cancer: A systematic review. Anticancer. Res. 2018, 38, 613-616.

106. Yu, X.; Le, Y.; Guo, J. Gastric juice MicroRNAs as potential biomarkers for the screening of gastric cancer. Cancer 2013, 119, 1618-1626. 
107. Pang, Q.; Ge, J.; Shao, Y.; Sun, W.; Song, H.; Xia, T.; Xiao, B.; Guo, J. Increased expression of long intergenic non-coding RNA LINC00152 in gastric cancer and its clinical significance. Tumor Biol. 2014, 35, 5441-5447. [CrossRef]

108. Yang, Y.; Shao, Y.; Zhu, M.; Li, Q.; Yang, F.; Lu, X.; Xu, C.; Xiao, B.; Sun, Y.; Guo, J. Using gastric juice lncRNA-ABHD11-AS1 as a novel type of biomarker in the screening of gastric cancer. Tumor Biol. 2016, 37, 1183-1188. [CrossRef]

109. Watanabe, Y.; Kim, H.S.; Castoro, R.J.; Chung, W.; Estecio, M.R.; Kondo, K.; Guo, Y.; Ahmed, S.S.; Toyota, M.; Itoh, F. Sensitive and specific detection of early gastric cancer with DNA methylation analysis of gastric washes. Gastroenterology 2009, 136, 2149-2158. [CrossRef]

110. Oishi, Y.; Watanabe, Y.; Yoshida, Y.; Sato, Y.; Hiraishi, T.; Oikawa, R.; Maehata, T.; Suzuki, H.; Toyota, M.; Niwa, H.; et al. Hypermethylation of Sox17 gene is useful as a molecular diagnostic application in early gastric cancer. Tumor Biol. 2012, 33, 383-393. [CrossRef]

111. Yamamoto, H.; Watanabe, Y.; Oikawa, R.; Morita, R.; Yoshida, Y.; Maehata, T.; Yasuda, H.; Itoh, F. BARHL2 methylation using gastric wash DNA or gastric juice exosomal DNA is a useful marker for early detection of gastric cancer in an H. pylori-independent manner. Clin. Transl. Gastroenterol. 2016, 7, e184. [CrossRef] [PubMed]

112. Baba, S.; Oishi, Y.; Watanabe, Y.; Oikawa, R.; Morita, R.; Yoshida, Y.; Hiraishi, T.; Maehata, T.; Nagase, Y.; Fukuda, Y.; et al. Gastric wash-based molecular testing for antibiotic resistance in Helicobacter pylori. Digestion 2011, 84, 299-305. [CrossRef] [PubMed]

113. Miyamoto, S.; Watanabe, Y.; Oikawa, R.; Ono, S.; Mabe, K.; Kudo, T.; Yamamoto, H.; Itoh, F.; Kato, M.; Sakamoto, N. Analysis of Helicobacter pylori genotypes in clinical gastric wash samples. Tumor Biol. 2016, 37, 10123-10132. [CrossRef] [PubMed]

114. Oikawa, R.; Watanabe, Y.; Miyamoto, S.; Sato, Y.; Ono, S.; Mabe, K.; Yamamoto, H.; Kato, M.; Itoh, F. Enrichment of Helicobacter pylori mutant strains after eradication therapy analyzed by gastric wash-based quantitative pyrosequencing. Tumor Biol. 2017, 39. [CrossRef] [PubMed]

115. Watanabe, Y.; Oikawa, R.; Kodaka, Y.; Sato, Y.; Ono, S.; Kenmochi, T.; Suzuki, H.; Futagami, S.; Kato, M.; Yamamoto, H.; et al. Cancer-related genetic variants of Helicobacter pylori strains determined using gastric wash-based whole genome analysis with single-molecule real-time technology. Int. J. Cancer 2020. [CrossRef]

(C) 2020 by the authors. Licensee MDPI, Basel, Switzerland. This article is an open access article distributed under the terms and conditions of the Creative Commons Attribution (CC BY) license (http://creativecommons.org/licenses/by/4.0/). 